Article

\title{
In Vitro-In Vivo Correlations Based on In Vitro Dissolution of Parent Drug Diltiazem and Pharmacokinetics of Its Metabolite
}

\author{
Constantin Mircioiu ${ }^{1}$, Valentina Anuta ${ }^{2}{ }^{\circ}$, Ion Mircioiu ${ }^{3}$, Adrian Nicolescu ${ }^{4}$ and \\ Nikoletta Fotaki $5, *$ (D) \\ 1 Department of Applied Mathematics and Biostatistics, Faculty of Pharmacy, "Carol Davila" University of \\ Medicine and Pharmacy, 020956 Bucharest, Romania \\ 2 Department of Physical and Colloidal Chemistry, Faculty of Pharmacy, "Carol Davila" University of \\ Medicine and Pharmacy, 020956 Bucharest, Romania \\ 3 Department of Biopharmacy and Pharmacokinetics, Titu Maiorescu University, 004051 Bucharest, Romania \\ 4 Department of Medicine, Queen's University, Kingston, ON K7L 3N6, Canada \\ 5 Department of Pharmacy and Pharmacology, University of Bath, Claverton Down, Bath BA2 7AY, UK \\ * Correspondence: n.fotaki@bath.ac.uk; Tel.: +44-1225-386728; Fax: +44-1225-386114
}

Received: 5 June 2019; Accepted: 7 July 2019; Published: 16 July 2019

\begin{abstract}
In this study a novel type of in vitro-in vivo correlation (IVIVC) is proposed: The correlation of the in vitro parent drug dissolution data with the in vivo pharmacokinetic data of drug's metabolite after the oral administration of the parent drug. The pharmacokinetic data for the parent drug diltiazem (DTZ) and its desacetyl diltiazem metabolite (DTZM) were obtained from an in vivo study performed in 19 healthy volunteers. The pharmacokinetics of the parent drug and its metabolite followed a pseudomono-compartmental model and deconvolution of the DTZ or DTZM plasma concentration profiles was performed with a Wagner-Nelson-type equation. The calculated in vivo absorption fractions were correlated with the in vitro DTZ dissolution data obtained with USP 2 apparatus. A linear IVIVC was obtained for both DTZ and DTZM, with a better correlation observed for the case of the metabolite. This type of correlation of the in vitro data of the parent compound with the in vivo data of the metabolite could be useful for the development of drugs with active metabolites and prodrugs.
\end{abstract}

Keywords: in vitro-in vivo correlation (IVIVC); diltiazem; mathematical modeling; metabolites; dissolution

\section{Introduction}

One of the goals of in vitro-in vivo correlations (IVIVCs) is the estimation of the in vivo release of an active substance from orally administered pharmaceutical formulations based on in vitro dissolution data. For extended release formulations, reasonable linear correlations have been obtained from a number of IVIVC studies [1-5]. In other cases, linear correlations were not satisfactory [6-9], or the data could not be correlated $[2,10,11]$. Although in the case of extended release formulations linear relationships are frequently obtained, both the United States Pharmacopoeia (USP) and the Food and Drug Administration (FDA) state that non-linear models are also acceptable to describe IVIVCs [12-14]. Non-linear models have been proposed by Polli et al. and Dunne et al. [15-17]. Model-independent methods are commonly used for the development of IVIVCs, but model-dependent methods are also applied [15-20]. For example, Dunne et al. started from survival curve methods considering the time at which a drug enters the solution (in vitro or in vivo) as a random variable and correlated the in vitro and in vivo parameters postulating different relations between distribution 
functions or their probability densities $[16,17]$. The distribution functions were obtained by cumulative dissolution and the probability densities were determined by the rate at which the drug is released from the pharmaceutical formulation. These non-linear models were considered as scientifically sound IVIVCs that contrast with the "empirical" non-linear functions such as the sigmoid, Weibull, Higuchi, or Hixson-Crowell methods [21]. All these models remain essentially empirical, and the more complex the model is the more unstable is the fitting algorithm and the risk of non-uniqueness of the solutions [22,23].

Diltiazem (DTZ), a benzothiazepine calcium channel blocker, has been widely used in the treatment of stable, variant, and unstable angina pectoris, systemic hypertension, and supraventricular tachycardias [24,25]. It is subjected to extensive and highly variable hepatic first-pass metabolism by CYP3A4, and only $2 \%-4 \%$ of the unchanged drug is excreted in the urine. The pharmacokinetics of DTZ in healthy volunteers indicated a biphasic elimination with a distribution half-life of $0.3 \pm$ $0.2 \mathrm{~h}$, an elimination half-life of $3.1 \pm 1 \mathrm{~h}$ and an apparent volume of distribution of $5.3 \pm 1.7 \mathrm{~L} / \mathrm{kg}$ after intravenous (i.v.) administration of $15 \mathrm{mg}$, and an elimination half-life of $3.2 \pm 1.3 \mathrm{~h}$ after oral administration of $60 \mathrm{mg}$ [26]. The absolute bioavailability of DTZ ranged from $24 \%$ to $74 \%$ (mean $42 \% \pm$ $18 \%$ ), and the inter-individual variability may be explained by the highly variable first-pass effect [24]. Non-linearity and a slight increase of the half-life were observed when the dose was increased. Notably, in young healthy volunteers DTZ did not show linear kinetics between single and multiple doses [27].

DTZ has several metabolites in humans: Desacetyl DTZ (DTZM), N-monodesmethyl DTZ, desacetyl N-monodesmethyl DTZ, and desacetyl DTZ N-oxide, with average maximum plasma concentrations of $10 \%, 15 \%, 26 \%$, and $13 \%$, respectively, of the mean maximum DTZ concentration [28]. Therefore, the analysis of the pharmacokinetics of DTZ and its metabolites, as well as the development of IVIVCs can be useful in improving the general administration schedule, the personalization of therapy and the development of DTZ formulations for oral administration.

The aim of this study was to develop IVIVCs for orally administered DTZ formulations. Apart from the traditional IVIVC approach in which the in vitro drug dissolution is correlated with its in vivo absorption calculated by deconvolution, a novel method was developed. The in vitro dissolution of DTZ was correlated to the in vivo absorption estimated by a deconvolution method that uses the pharmacokinetic data of the active metabolite (DTZM). This approach could be valuable for the development of IVIVCs for drugs with significant plasma levels of metabolites.

\section{Materials and Methods}

\subsection{Chemicals and Reagents}

Diltiazem hydrochloride (batch 4) and haloperidol (batch 1) reference standards were purchased from the European Directorate for the Quality of Medicines (EDQM, Strasbourg, France), while desacetyl diltiazem hydrochloride (batch JOC143) was obtained from the United States Pharmacopeia (USP, Rockville, MD, USA). Cardiazem ${ }^{\circledR} 60 \mathrm{mg}$ tablets (Hoechst Marion Roussel, batch number 1099841) were used for the in vitro and in vivo studies.

HPLC gradient grade acetonitrile and methanol were purchased from Merck KGaA (Darmstadt, Germany), whereas HPLC grade methyl tert-butyl ether was acquired from Sigma-Aldrich (Taufkirchen, Germany). All other reagents were of analytical grade and used without further purification. Ultrapure water (resistivity $18.2 \mathrm{M} \Omega \cdot \mathrm{cm}$ at $25^{\circ} \mathrm{C}$, Total Organic Carbon (TOC) $<5 \mathrm{ppb}$ ) was obtained from a Milli-Q (Millipore, Milford, MA, USA) water purification system. Blank human plasma was obtained from the Army Centre of Transfusion Hematology (Bucharest, Romania).

\subsection{In Vitro Dissolution Studies}

Dissolution studies of Cardiazem ${ }^{\circledR} 60$ mg tablets were performed using a USP 2 dissolution apparatus (DT 800 Erweka GmbH, Heusenstamm, Germany) at $75 \mathrm{rpm}$. The dissolution medium (ultrapure water, $900 \mathrm{~mL}$ ) was deaerated and maintained at $37 \pm 0.5^{\circ} \mathrm{C}$. Aliquots of $5 \pm 0.1 \mathrm{~mL}$ were 
withdrawn at 10, 15, 20,30, 60, 120, and $180 \mathrm{~min}$, and immediately replaced with an equal volume of fresh medium maintained at the same temperature. The samples were filtered through a $0.45 \mu \mathrm{m}$ Teflon ${ }^{\circledR}$ filter, and the drug concentrations were determined by measuring the absorbance of each sample at $237 \mathrm{~nm}$ on a V-530 UV-VIS spectrophotometer (JASCO Ltd., Tokio, Japan). Diltiazem concentrations were calculated from linear calibration curves. Dissolution data for each compound are reported as mean values of 12 replicates, and the coefficient of variation $(\mathrm{CV} \%$; [mean value/standard deviation] $\times 100 \%$ ) was calculated.

\subsection{Clinical Study}

In vivo data were obtained in a pharmacokinetic study after administration of two $60 \mathrm{mg}$ Cardiazem ${ }^{\circledR}$ tablets to 19 healthy volunteers in a single-dose study under fasting conditions.

The study was carried out in accordance with the basic principles defined in the Helsinki Declaration of 1964 as revised in 2013, as well as with the International Conference on Harmonization (ICH) Good Clinical Practice regulations. The study was conducted at the National Institute for Aeronautical and Space Medicine «Gen. Dr. Av. Victor Atanasiu» within the Central Clinical Emergency Military Hospital in Bucharest (Romania).

The study protocol (protocol code: DILTZARE155/2002) was approved by the Institutional Ethics Committee of Biopharmacy \& Pharmacol Res S.A. (approval number 32, 4 July 2007), as well as by the Romanian National Agency for Medicines and Medical Devices (approval number 337, 24 July 2007).

The study subjects $(n=19)$ were of Caucasian race, aged between 19 and 30 years $(24.3 \pm 3.34)$ and with a body mass index between 19 and 27 (22.43 \pm 1.87$)$. All subjects were healthy according to their medical and social history, physical examination, and laboratory tests. The subjects had no history of drug or alcohol abuse, hypersensitivity to the investigational products, and did not take any medication for two weeks before dosing. Alcohol, tobacco, as well as caffeine containing beverages were forbidden for $48 \mathrm{~h}$ before as well as during the study. All subjects gave written informed consent prior to study enrolment and were allowed to terminate their participation in the trial at any time, without restrictions. Standard meals were provided to the subjects at four and nine hours after drug administration.

Venous blood samples $(5 \mathrm{~mL})$ were collected into heparinized tubes through a catheter inserted in the antecubital vein before (time 0 ) and at $0.5,1,1.5,2,2.5,3,3.5,4,5,6,7,8,10,12$, and $24 \mathrm{~h}$ after drug administration. Blood samples were centrifuged at $5{ }^{\circ} \mathrm{C}$ for six minutes at approx. $3000 \mathrm{rpm}$. Plasma was separated in two equal aliquots $(1.2-1.3 \mathrm{~mL})$, transferred to labeled $1.5 \mathrm{~mL}$ polypropylene tubes and immediately frozen and stored at $\mathrm{a}<-20^{\circ} \mathrm{C}$ until analysis.

\subsection{Sample Treatment}

Plasma samples (500 $\mu \mathrm{L}$ ) were transferred to $10 \mathrm{~mL}$ disposable polypropylene tubes, to which $100 \mu \mathrm{L}$ internal standard (IS) solution (containing $10 \mu \mathrm{g} / \mathrm{mL}$ haloperidol in methanol), $200 \mu \mathrm{L} 0.2 \mathrm{M}$ dipotassium phosphate buffer $\mathrm{pH}=9$ and $3 \mathrm{~mL}$ methyl tert-butyl ether were added. The tubes were vortex-mixed for $10 \mathrm{~min}$ and then centrifuged for $10 \mathrm{~min}$ at $4000 \mathrm{rpm}$. Of the organic layer $2.5 \mathrm{~mL}$ were removed and extracted with $200 \mu \mathrm{L} 0.025 \mathrm{M}$ phosphoric acid solution. After shaking for $10 \mathrm{~min}$ and centrifugation for $10 \mathrm{~min}$ at $4000 \mathrm{rpm}, 25 \mu \mathrm{L}$ of the acidic aqueous phase were analyzed by HPLC.

\subsection{Preparation of Standard Solutions and Quality Control Samples}

The stock solutions of DTZ and DTZM were prepared by dissolving an appropriate amount of each reference standard in methanol to yield concentrations of $100 \mu \mathrm{g} / \mathrm{mL}$ and $50 \mu \mathrm{g} / \mathrm{mL}$, respectively, and serially diluted with the same solvent. $10 \mu \mathrm{L}$ of the diluted solutions of each analyte were spiked into $80 \mu \mathrm{L}$ of blank plasma, in order to obtain the calibration standard solutions with final concentrations of $2.5,5,10,25,50,100,250$, and $500 \mathrm{ng} / \mathrm{mL}$ for DTZ and 1.25, 2.5, 5, 12.5, 25, 50125 , and $250 \mathrm{ng} / \mathrm{mL}$ for DTZM.

Quality control (QC) samples were prepared similarly, in order to obtain concentrations at the lower limit of quantification (LLOQ; $2.5 \mathrm{ng} / \mathrm{mL}$ for DTZ and $1.25 \mathrm{ng} / \mathrm{mL}$ for DTZM), and at low (QC low 
$=7.5 \mathrm{ng} / \mathrm{mL}$ DTZ and $3.75 \mathrm{ng} / \mathrm{mL}$ DTZM $)$, medium $\left(\mathrm{QC}_{\text {med }}=150 \mathrm{ng} / \mathrm{mL}\right.$ DTZ and $75 \mathrm{ng} / \mathrm{mL}$ DTZM$)$, and high $\left(\mathrm{QC}_{\text {high }}=300 \mathrm{ng} / \mathrm{mL}\right.$ DTZ and $150 \mathrm{ng} / \mathrm{mL}$ DTZM $)$ concentration levels.

All stock and standard solutions were protected from light and stored at $-20^{\circ} \mathrm{C}$ until use.

\subsection{Chromatographic Analysis}

Chromatographic analyses were performed on a Waters liquid chromatographic system (Milford, MA 01757, USA) consisting of a quaternary gradient system (600E Multisolvent Delivery System), in line degasser (Waters model AF), UV tunable absorbance detector (Waters model 486), and auto sampler (Waters model 717 plus). Empower Pro software (Waters, Milford, MA 01757, USA) was used to control the system, acquire and process data. The UV detector was set at $235 \mathrm{~nm}$. The chromatographic separation was achieved on an Ascentis $5 \mathrm{C} 18,5-\mu \mathrm{m} 150 \times 2.1 \mathrm{~mm}$ column (Supelco, Bellefonte, PA 16823 , USA) at a constant temperature $\left(35^{\circ} \mathrm{C}\right)$. The mobile phase consisted of an isocratic mixture of $0.025 \mathrm{M}$ potassium di-hydrogen phosphate buffer containing $0.2 \%$ triethylamine adjusted to $\mathrm{pH} 2.2$ and acetonitrile in a $72: 28(v / v)$ ratio, and delivered at $0.35 \mathrm{~mL} / \mathrm{min}$ flow rate. Of each sample $25 \mu \mathrm{L}$ were injected into the chromatographic column.

Method validation was performed in accordance with the bioanalytical method validation guidelines of the FDA, including selectivity, linearity, limits of quantification, accuracy, precision, recovery, dilution effects, and stability [29]. Assay specificity was evaluated in relation to interferences from the endogenous matrix components of drug free plasma samples of six different origins. The calibration curves of both DTZ and DTZM were constructed by plotting DTZ or DTZM to IS peak area ratios versus concentration $(\mathrm{ng} / \mathrm{mL})$, using data obtained from triplicate analysis of the calibration standard solution (in the range $2.5-500 \mathrm{ng} / \mathrm{mL}$ for DTZ and $1.25-250 \mathrm{ng} / \mathrm{mL}$ for DTZM). The lower limit of quantification (LLOQ) was set as the lowest concentration on the calibration curve. Within-run and between runs precision and accuracy were estimated by analyzing five replicates of the LLOQ and the QC samples in a single analytical run and on five consecutive days, respectively. The acceptance criteria for precision and accuracy were: Relative Standard Deviation (RSD) $\% \leq 15 \%$ and bias within $\pm 15 \%$ for the QC samples and RSD $\% \leq 20 \%$ and bias within $\pm 20 \%$ for the LLOQ samples. The absolute recovery of DTZ and DTZM was determined using five replicates of the three concentration level QC samples. Bench-top, extract, stock solution, freeze-and-thaw, long-term, and post-preparative stability studies were also performed to evaluate the stability of both DTZ and DTZM.

\subsection{Treatment of In Vivo Data}

Estimation of pharmacokinetic parameters of the in vivo parameters by non-compartmental analysis was performed using subroutines of the KINETICA 4.2 software (Innaphase Corp, Philadelphia, PA 19102, USA). The maximum concentration $\left(C_{\max }\right)$ and the corresponding peak times $\left(\mathrm{T}_{\max }\right)$ were determined from the individual drug plasma concentration-time profiles. The elimination rate constant $\left(k_{e}\right)$ was obtained from the least-square fitted terminal log-linear portion of the plasma concentration-time profile. The elimination half-life $\left(t_{1 / 2}\right)$ was calculated as $0.693 / k_{e}$. The area under the curve to the last measurable concentration $\left(\mathrm{AUC}_{0-\mathrm{t}}\right)$ was calculated by the trapezoidal rule method. The area under the curve extrapolated to infinity $\left(\mathrm{AUC}_{0-\infty}\right)$ was calculated as $\mathrm{AUC}_{0-\mathrm{t}}+C_{t} / k_{e}$, where $C_{t}$ is the last measurable concentration. Shapiro-Wilk statistic W-test (SW-W) was used to evaluate normality of data distribution, with a $p<0.05$ set as threshold for statistical significance.

Compartmental analysis of the in vivo data was performed using TOPFIT 2.0 software (Thomae $\mathrm{GmbH}$, Germany). Fitting performance was assessed based on the Akaike (AIC) and Schwarz (SC) criteria (both based on the sum of "errors" corrected by a "penalty" function proportional to the number of parameters model: $A I C=N \cdot \ln S S+2 p ; S C=N \cdot \ln S S+p \cdot \ln N$ ) [22], where $N$ is the sample size (i.e., number of data points), $p$ represents the number of model parameters and $S S$ is the sum of squares error.

The significance of the differences in the fitting performance of two nested models, a more complicated one (with $p$ parameters) and a simpler one (with $q$ parameters, $q<p$ ), was evaluated by 
comparing the relative increase in the sum of squares $\left(\frac{S S_{q}-S S_{p}}{S S_{p}}\right)$ with the relative decrease in degrees of freedom $\left(\frac{d f_{q}-d f_{p}}{d f_{p}}\right)$ going from the more complicated to the simpler model, based on the F ratio:

$$
F=\frac{S S_{q}-S S_{p}}{S S_{p}} \frac{d f_{p}}{d f_{q}-d f_{p}}
$$

where the degrees of freedom $d f$ equals the difference between the sample size $N$ and the number of parameters of each model $\left(d f_{p}=N-p\right.$ and $d f_{q}=N-q$, respectively).

A model is considered more efficient if it is simple, has a minimum number of parameters, is "phenomenologically" justified and errors are comparable with experimental errors and physiological variability.

\subsection{Model-Independent Estimation of In Vivo Absorption/Dissolution by the Deconvolution of} In Vivo Pharmacokinetics

The fraction of drug absorbed was calculated using the Wagner-Nelson equation [30]:

$$
F R A\left(t_{i}\right)=\frac{c_{p_{d}}\left(t_{i}\right)+\int_{0}^{t_{i}} k_{e} c_{p d} d t}{\int_{0}^{\infty} k_{e} c_{p d} d t}=\frac{c_{p_{d}}\left(t_{i}\right)+k_{e} A U C(P D)_{0-t_{i}}}{k_{e} A U C(P D)_{0-\infty}},
$$

where, $F R A\left(t_{i}\right)$, fraction of the drug absorbed at time $t_{i} ; c_{p_{d}}\left(t_{i}\right)$, plasma concentration of the parent drug at time $t_{i} ; k_{e}$, elimination rate constant for the parent drug; $A U C(P D)_{0-t_{i}}$, area under the concentration-time curve of the parent drug from time 0 to time $t_{i} ; A U C(P D)_{0-\infty}$, area under the concentration-time curve of the parent drug from time 0 to infinity.

In the case of metabolites, a Wagner-Nelson type equation was applied for the calculation of the apparent fraction of the metabolized drug (FRM):

$$
F R M\left(t_{i}\right)=\frac{c_{m}\left(t_{i}\right)+\int_{0}^{t_{i}} k_{e}^{m} c_{m} d t}{\int_{0}^{\infty} k_{e}^{m} c_{m} d t}=\frac{c_{m}\left(t_{i}\right)+k_{e}^{m}[A U C-M]_{0-t_{i}}}{k_{e}^{m}[A U C-M]_{0-\infty}},
$$

where, $F R M\left(t_{i}\right)$, fraction of the metabolized drug at time $t_{i} ; c_{m}\left(t_{i}\right)$, plasma concentration of the metabolite at time $t_{i} ; k_{e}^{m}$, elimination rate constant of the metabolite.

The elimination rate constant was estimated by performing both a non-compartmental analysis (linear regression of the last points of the logarithmic data) and a one-compartmental modeling of the mean plasma levels.

If the absorption and metabolism can be assumed to be rapid, $F R M\left(t_{i}\right)$ could be considered an estimation of $F R A\left(t_{i}\right)$. Based on this assumption, an in vitro dissolution-in vivo metabolism correlation could be expected.

\section{Results}

\subsection{In Vitro Dissolution of Diltiazem}

The individual DTZ dissolution profiles in water are presented in Figure 1 and the mean \% dissolved over time are shown in Table 1. A $80.92 \%$ DTZ dissolved is observed after $3 \mathrm{~h}$. Since DTZ is lipophilic $(\log P 2.7)$ [31], its administration as a hydrochloride salt helps the rapid dissolution in the stomach. Its precipitation in the intestine is likely unavoidable $(\mathrm{pKa}=8.06)$ and could account for its absorption variability. Based on the small variability of the in vitro dissolution profiles, as revealed by the low values of $\mathrm{CV} \%$ (Table 1), the mean dissolution profile can be used for the development of IVIVCs. 


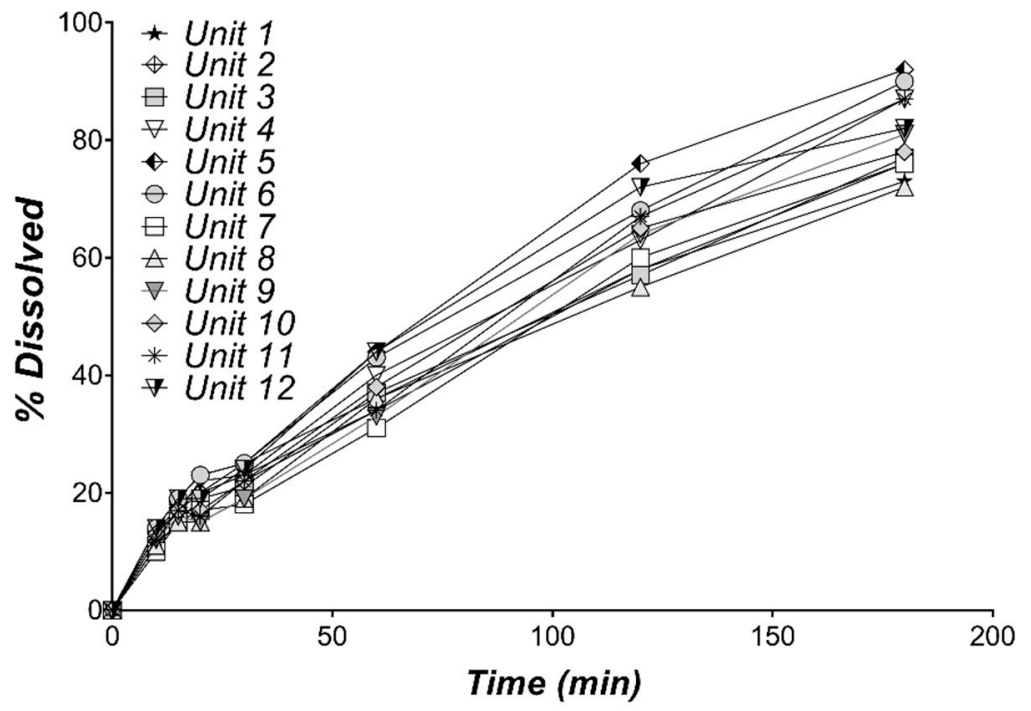

Figure 1. Individual in vitro dissolution profiles of DTZ from $60 \mathrm{mg}$ Cardiazem ${ }^{\circledR}$ tablets in $900 \mathrm{~mL}$ water, using USP Apparatus 2, at $75 \mathrm{rpm}(n=12)$.

Table 1. In vitro dissolution of DTZ from $60 \mathrm{mg}$ Cardiazem ${ }^{\circledR}$ tablets in $900 \mathrm{~mL}$ water, using USP Apparatus 2, at $75 \mathrm{rpm}(n=12)$.

\begin{tabular}{ccc}
\hline Time (min) & Dissolved (\%) & CV (\%) \\
\hline 10 & 12.42 & 10.56 \\
15 & 17.00 & 9.04 \\
20 & 18.67 & 15.88 \\
30 & 22.17 & 11.19 \\
60 & 37.67 & 10.46 \\
120 & 63.58 & 9.66 \\
180 & 80.92 & 8.29 \\
\hline
\end{tabular}

\subsection{Chromatographic Method Validation}

No interference between the endogenous matrix components and DTZ or DTZM was observed, indicating selectivity of the HPLC method in the plasma samples (Figure 2). Calibration curves were linear over the concentration range $2.5-500 \mathrm{ng} / \mathrm{mL}$ for DTZ $\left(Y=1.21 \mathrm{e}-003 \mathrm{X}+2.03 \mathrm{e}-003 ; \mathrm{R}^{2}=0.9997\right)$, and $1.25-250 \mathrm{ng} / \mathrm{mL}$ for DTZM $\left(\mathrm{Y}=1.59 \mathrm{e}-003 \mathrm{X}+2.33 \mathrm{e}-004 ; \mathrm{R}^{2}=0.9997\right)$.

The LLOQ was $2.5 \mathrm{ng} / \mathrm{mL}$ for DTZ and $1.25 \mathrm{ng} / \mathrm{mL}$ for DTZM, suggesting a good sensitivity of the analytical method.

Both within-run and between runs accuracy and precision were within the accepted limits (Table 2) for the LLOQ and all the QC samples. The within-run precision (RSD \%) ranged between $1.19 \%$ and $5.71 \%$, whereas accuracy ( $\%$ bias versus nominal concentration) ranged between $0.25 \%$ and $3.76 \%$; the between run precision (RSD \%) was between $3.53 \%$ and $8.03 \%$ whereas the $\%$ bias versus the nominal concentration was lower than $6 \%$ (Table 2).

The mean absolute recovery in plasma was $105.19 \% \pm 4.81 \%$ for DTZ, $96.52 \pm 5.59$ for DTZM and $91.11 \pm 3.32$ for the IS, indicating lack of interference from the sample preparation method. Dilution effect was not observed either for DTZ or DTZM by means of a five-fold dilution with blank plasma. 


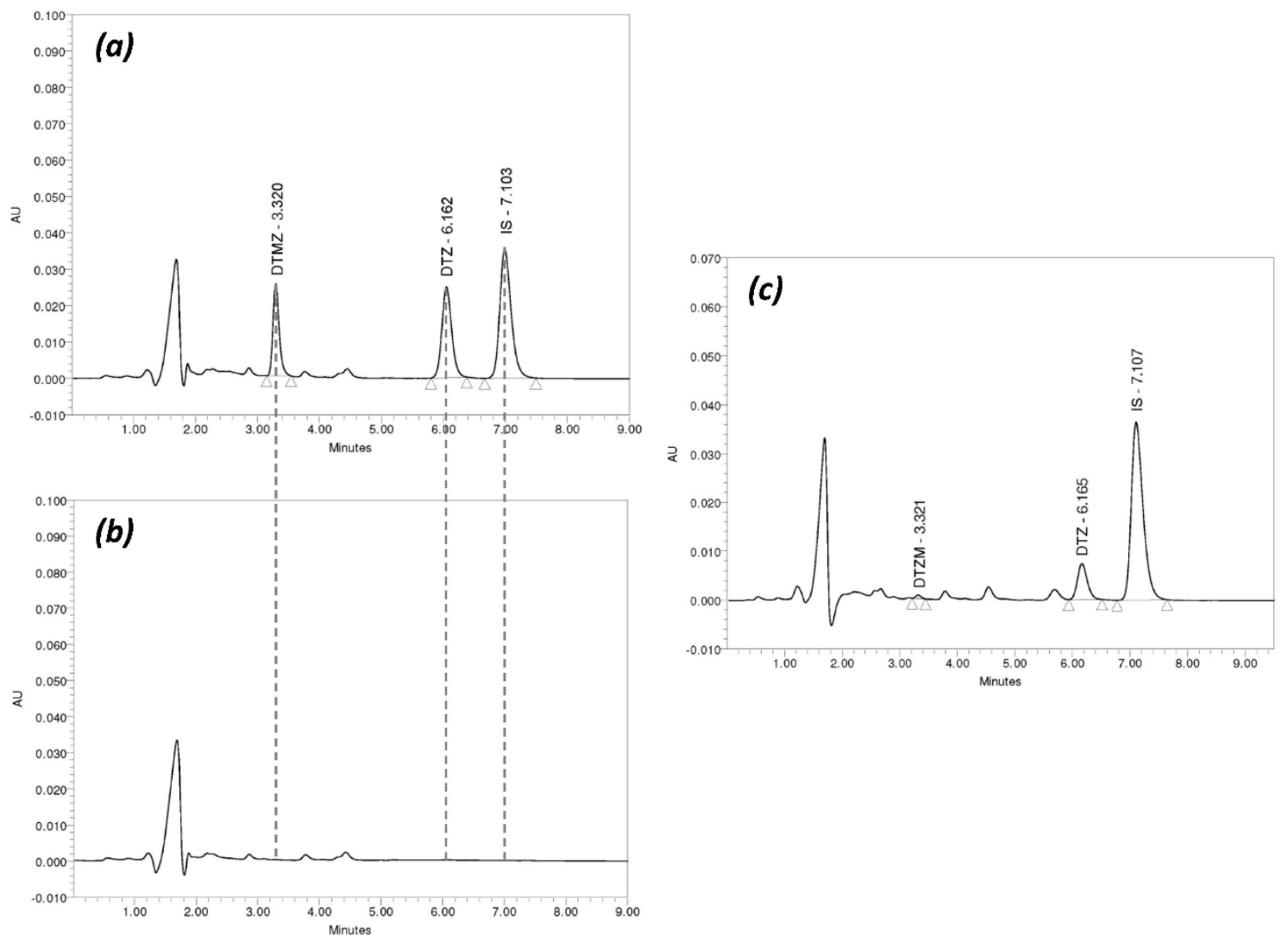

Figure 2. Typical HPLC chromatograms of DTZ and DTZM in plasma: (a) Chromatogram of a standard sample containing DTZ (500 ng/mL) and DTZM (250 ng/mL) and internal standard (IS); (b) chromatogram of blank plasma; (c) chromatogram of a plasma sample obtained from one on the study subjects two hours after drug administration (DTZ-154.4 ng/mL, DTZM-3.9 ng/mL).

Table 2. Accuracy and precision data for the determination of diltiazem (DTZ) and desacetyl DTZ (DTZM) in human plasma.

\begin{tabular}{|c|c|c|c|c|c|c|c|c|}
\hline \multirow{2}{*}{$\begin{array}{l}\text { Sample } \\
\text { Code }\end{array}$} & \multicolumn{4}{|c|}{ DTZ } & \multicolumn{4}{|c|}{ DTZM } \\
\hline & $\begin{array}{c}\text { Nominal } \\
\text { conc. } \\
(\mathrm{ng} / \mathrm{mL})\end{array}$ & $\begin{array}{c}\text { Measured } \\
\text { conc. }(\text { Mean } \pm \\
\text { SD, } \mathrm{ng} / \mathrm{mL})\end{array}$ & RSD (\%) & Bias (\%) & $\begin{array}{c}\text { Nominal } \\
\text { conc. } \\
\text { (ng/mL) }\end{array}$ & $\begin{array}{c}\text { Measured } \\
\text { conc. }(\text { Mean } \pm \\
\text { SD, } \mathrm{ng} / \mathrm{mL})\end{array}$ & RSD (\%) & Bias (\%) \\
\hline \multicolumn{9}{|c|}{ Within-run } \\
\hline LLOQ & 2.5 & $2.49 \pm 0.14$ & 5.71 & -0.56 & 1.25 & $1.26 \pm 0.05$ & 3.79 & 0.40 \\
\hline $\mathrm{QC}_{\text {low }}$ & 7.5 & $7.48 \pm 0.29$ & 3.89 & -0.25 & 3.75 & $3.72 \pm 0.14$ & 3.73 & -0.85 \\
\hline $\mathrm{QC}_{\text {med }}$ & 150 & $148.83 \pm 2.76$ & 1.85 & -0.78 & 75 & $72.18 \pm 1.65$ & 2.29 & -3.76 \\
\hline $\mathrm{QC}_{\text {high }}$ & 300 & $310.46 \pm 3.70$ & 1.19 & 3.49 & 150 & $146.26 \pm 2.47$ & 1.69 & -2.49 \\
\hline \multicolumn{9}{|c|}{ Between runs } \\
\hline LLOQ & 2.5 & $2.63 \pm 0.17$ & 6.43 & 5.04 & 1.25 & $1.32 \pm 0.07$ & 5.32 & 5.60 \\
\hline $\mathrm{QC}_{\text {low }}$ & 7.5 & $7.52 \pm 0.31$ & 4.15 & 0.24 & 3.75 & $3.74 \pm 0.30$ & 8.03 & -0.30 \\
\hline$\hat{\mathrm{QC}}_{\text {med }}$ & 150 & $146.22 \pm 6.68$ & 4.57 & -2.52 & 75 & $73.71 \pm 3.42$ & 4.64 & -1.72 \\
\hline QC high & 300 & $298.91 \pm 12.52$ & 4.19 & -0.36 & 150 & $149.37 \pm 5.27$ & 3.53 & -0.42 \\
\hline
\end{tabular}

Both DTZ and DTZM were stable in plasma for $5 \mathrm{~h}$ at room temperature, for $27 \mathrm{~h}$ during the chromatographic analysis (placed in autosampler) and for 97 days at $-20{ }^{\circ} \mathrm{C}$. There was no observed degradation of the samples under three cycles of freezing and thawing.

Typical HPLC chromatograms of DTZ and DTZM in plasma are presented in Figure 2. 


\subsection{Pharmacokinetics of Diltiazem and Its Metabolite}

The individual and mean plasma level profiles of DTZ and DTZM after oral administration of $120 \mathrm{mg}$ of DTZ (two $60 \mathrm{mg}$ Cardiazem ${ }^{\circledR}$ tablets) were relatively homogenously distributed in the concentration-time space (Figure 3). The data could be interpreted as revealing three clusters, i.e., three volunteers with high, one with low plasma levels, and the remaining 15 volunteers having homogenously distributed profiles. The plasma concentrations of the metabolite DTZM were approximately 20 times lower than those of the parent drug.

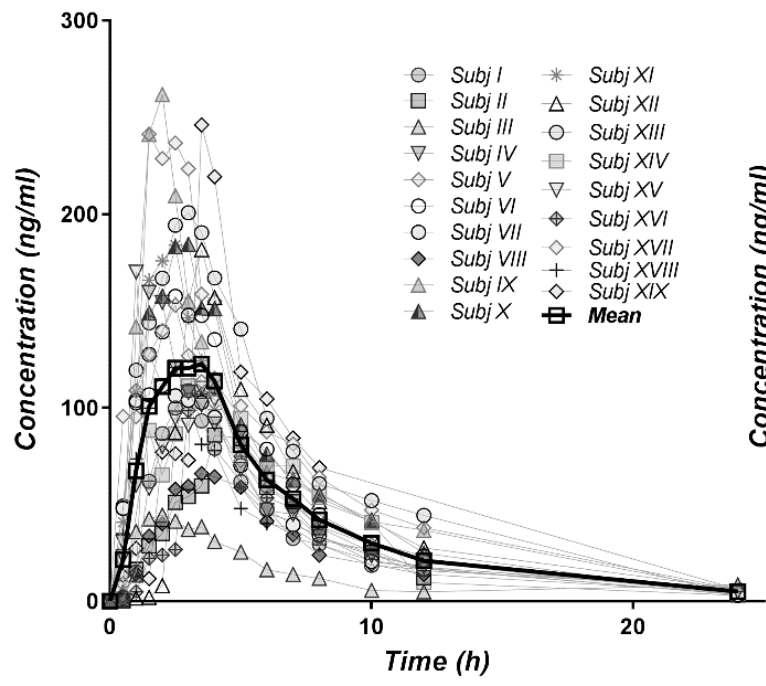

(a)

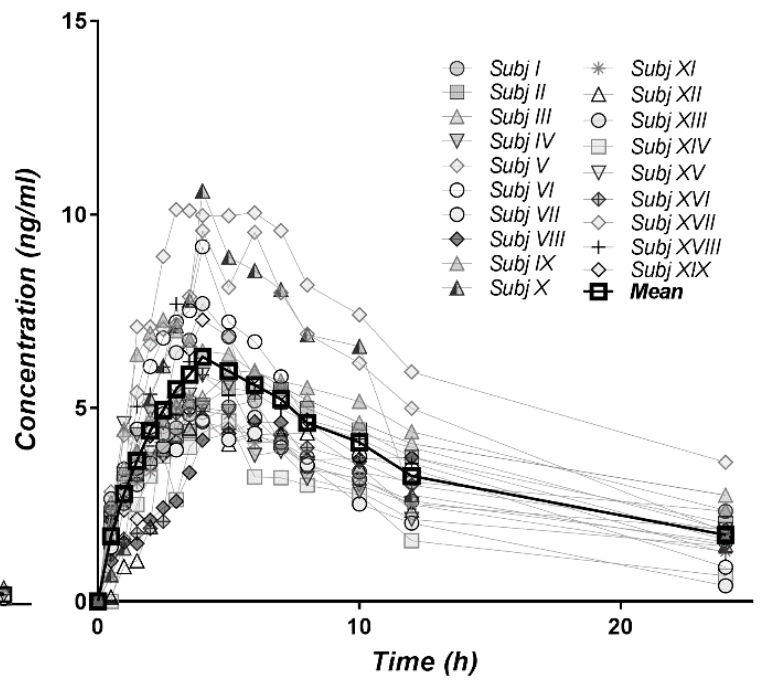

(b)

Figure 3. Individual and mean plasma concentration-time profiles for (a) DTZ and (b) DTZM after single dose oral administration of $120 \mathrm{mg}$ diltiazem $\left(2 \times 60 \mathrm{mg}\right.$ Cardiazem ${ }^{\circledR}$ tablets $)$ to 19 healthy subjects.

The distribution of the areas under curves of the plasma concentration profiles after the administration of $120 \mathrm{mg}$ of DTZ in the 19 healthy volunteers was approximately normal (Figure 4).
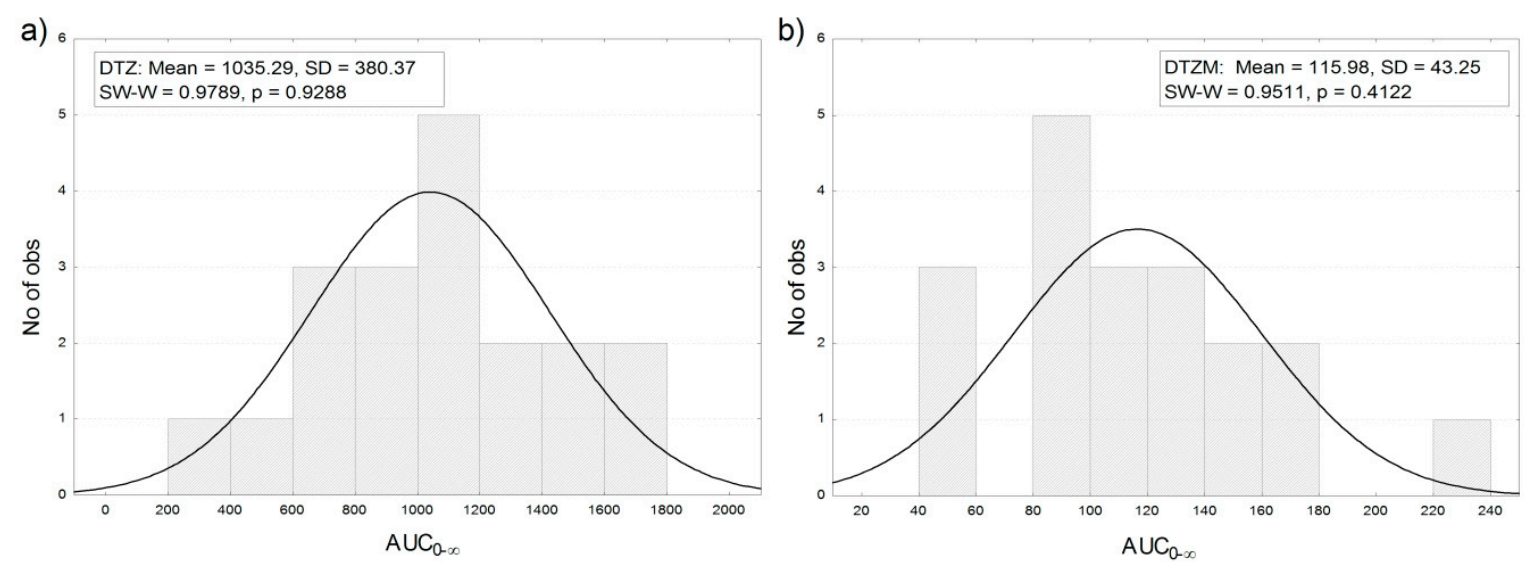

Figure 4. Frequency distribution of $\mathrm{AUC}_{0-\infty}$ for (a) DTZ and (b) DTZM after the oral administration of $120 \mathrm{mg}$ of DTZ in 19 healthy subjects (the observed significance level $p$ of the Shapiro-Wilk statistic W $(\mathrm{SW}-\mathrm{W})$ indicates normality of the distribution $(p<0.05))$.

The summary of the main pharmacokinetic parameters of DTZ and DTZM in the 19 healthy volunteers, estimated by non-compartmental analysis, is presented in Table 3. 
Table 3. Summary pharmacokinetic parameters of DTZ and DTZM in healthy subjects estimated by non-compartmental analysis.

\begin{tabular}{ccccc}
\hline \multirow{2}{*}{ Parameter } & \multicolumn{2}{c}{ DTZ } & \multicolumn{2}{c}{ DTZM } \\
\cline { 2 - 5 } & Mean & SD & Mean & SD \\
\hline $\mathrm{C}_{\max }(\mathrm{ng} / \mathrm{mL})$ & 154 & 59.6 & 6.66 & 1.98 \\
$\mathrm{~T}_{\max }(\mathrm{h})$ & 2.66 & 0.898 & 4 & 1.12 \\
$\mathrm{k}_{\mathrm{e}}(1 / \mathrm{h})$ & 0.157 & 0.0237 & 0.074 & 0.0325 \\
$\mathrm{t}_{1 / 2}(\mathrm{~h})$ & 4.51 & 0.655 & 11.2 & 5.25 \\
\hline
\end{tabular}

\subsection{Compartmental Modeling of Diltiazem and Its Metabolite Pharmacokinetics}

The pharmacokinetics of DTZ and DTZM were evaluated based on compartmental modeling. Based on work performed previously, it has been shown that the pharmacokinetics of the metabolites usually follow a pseudomono-compartmental model [32-34]. The pharmacokinetic modeling of DTZ and DTZM revealed that the mean plasma levels can be acceptably described by a one-compartment model after introducing a short lag-time (Figure 5). The use of the two compartmental model was just marginally better based on the Akaike and Schwarz criteria (Figure 6). Therefore, increase of the number of the parameters was not selected, as models with a high number of parameters are highly unstable, since small perturbations in the input data can lead to high differences in the solutions [23].

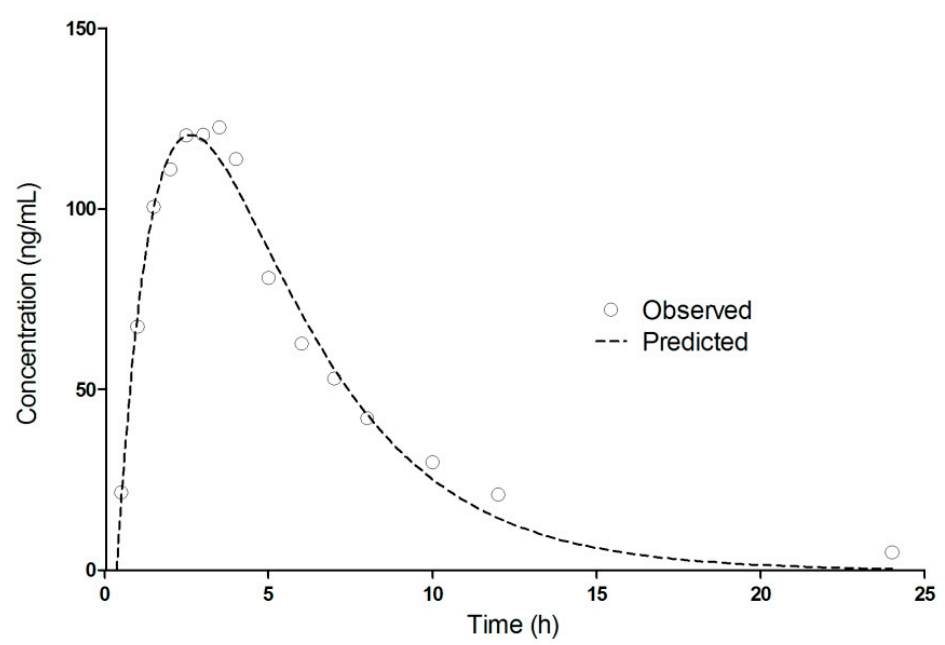

Figure 5. One-compartment pharmacokinetic modeling of DTZ mean plasma levels after oral administration of $120 \mathrm{mg}$ DTZ $\left(2 \times 60 \mathrm{mg}\right.$ Cardiazem $^{\circledR}$ tablets $)$ in 19 healthy subjects.

a)

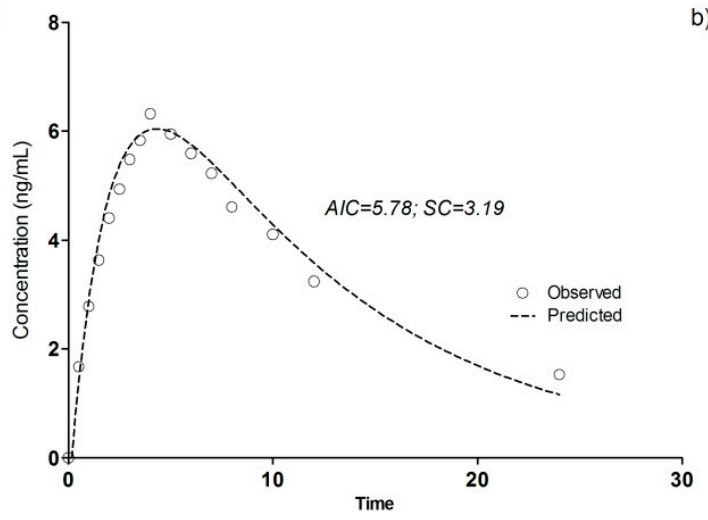

b)

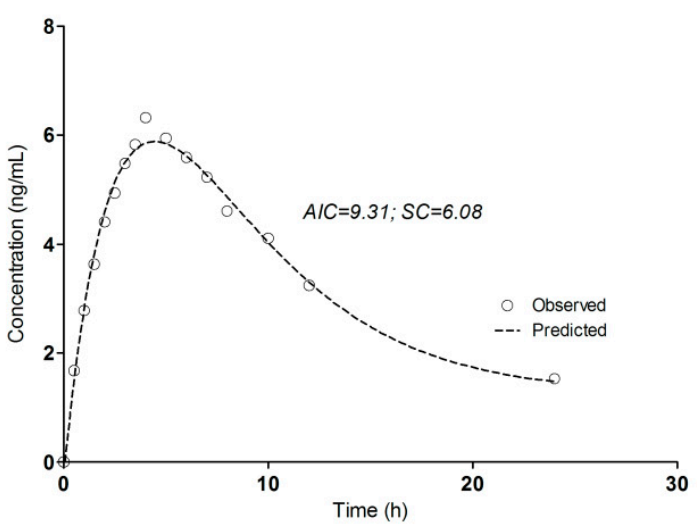

Figure 6. Pharmacokinetic modeling of DTZM mean plasma levels after oral administration of $120 \mathrm{mg}$ DTZ $\left(2 \times 60 \mathrm{mg}\right.$ Cardiazem ${ }^{\circledR}$ tablets $)$ in 19 healthy subjects. (a) One-compartment model; (b) two-compartment model. 
The derived pharmacokinetic parameters from the one compartmental modeling of the mean plasma levels of DTZ and DTZM after the oral administration of $120 \mathrm{mg}$ DTZ are summarized in Table 4.

Table 4. Pharmacokinetic parameters of DTZ and DTZM estimated by one-compartmental analysis of the mean concentration-time profiles after the oral administration of $120 \mathrm{mg}$ of DTZ to 19 healthy subjects.

\begin{tabular}{ccc}
\hline Parameter & DTZ & DTZM \\
\hline $\mathrm{k}_{\mathrm{e}}(1 / \mathrm{h})$ & 0.2861 & 0.0945 \\
$\mathrm{k}_{\mathrm{a}}(1 / \mathrm{h})$ & 0.0655 & 0.492 \\
$\mathrm{~T}_{\text {lag }}(\mathrm{h})$ & 0.36 & 0.162 \\
$\mathrm{C}_{\max }(\mathrm{ng} / \mathrm{mL})$ & 120.5 & 6.04 \\
$\mathrm{~T}_{\max }(\mathrm{h})$ & 2.51 & 4.20 \\
$\mathrm{AUC}_{0-\infty}(\mathrm{ng} / \mathrm{mL} \cdot \mathrm{h})$ & 800.9 & 94.66 \\
$\mathrm{t}_{1 / 2}(\mathrm{~h})$ & 2.42 & 7.34 \\
\hline
\end{tabular}

\subsection{Model-Independent Estimation of In Vivo Absorption/Dissolution}

The fractions of DTZ and DTZM absorbed over time as calculated by the Wagner-Nelson equations are presented in Figure 7. As the parent drug and metabolite follow a one-compartmental pharmacokinetic model (as presented in the previous section), this model independent deconvolution approach with the Wagner-Nelson method can be successfully applied to the in vivo DTZ and DTZM plasma concentration profiles.

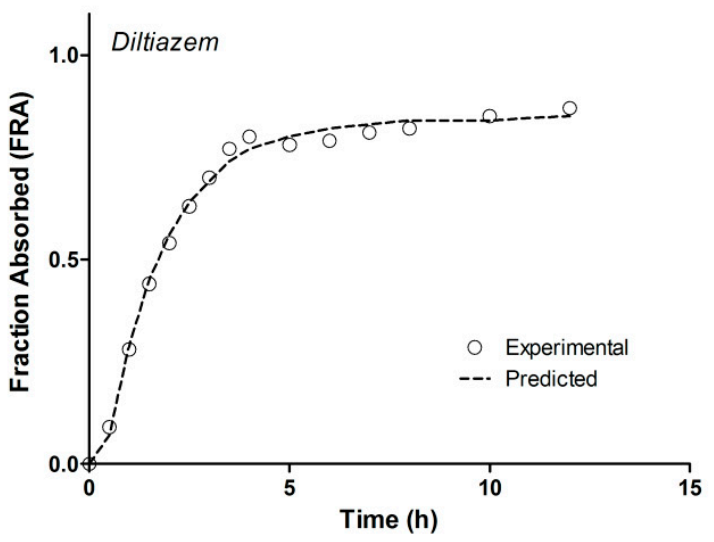

(a)

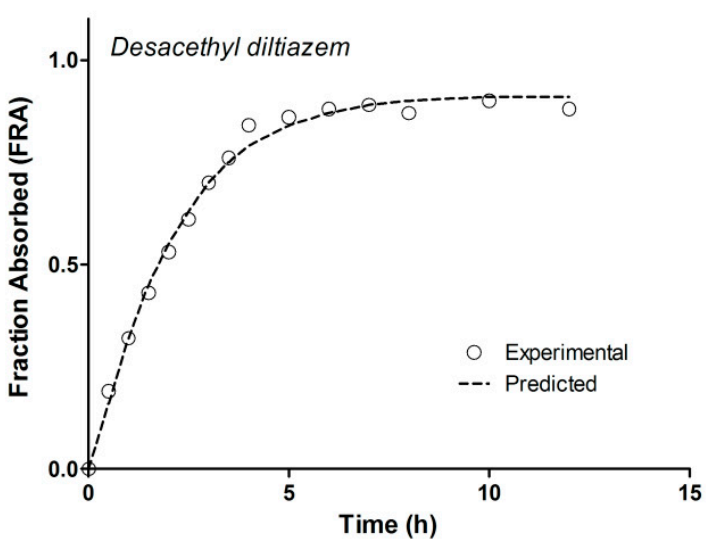

(b)

Figure 7. Fraction absorbed profiles calculated for (a) DTZ and (b) DTZM; observed: profiles calculated based on estimation of elimination rate constant with non-compartmental analysis, predicted: profiles calculated based on estimation of elimination rate constant with one-compartmental pharmacokinetic modeling.

The fraction absorbed profiles calculated based on estimation of elimination rate constant with both methods (non-compartmental analysis and one-compartmental pharmacokinetic modeling) were similar for DTZ and DTZM, revealing that the method used for the estimation of the elimination rate constant was robust. In the case of the DTZM, the elimination profile was simple and further metabolism was not observed. Furthermore, given the more polar character of DTZM compared to DTZ, its biliary excretion is less significant. Consequently, the variability of metabolite's elimination constant should be lower than that of the parent drug. This is an important argument for using the metabolite plasma levels rather than those of the parent drug for estimating the in vivo dissolution of the parent drug. The results obtained by following a Wagner-Nelson approach reflect the combination 
of the in vivo dissolution, absorption and metabolism of the parent drug. In this chain of processes, the slowest process determines the overall result.

\subsection{Correlation of Apparent Absorbed/Metabolized Fraction with In Vitro Dissolution of Diltiazem}

Since it is not possible to estimate separately the in vivo dissolution, gastric empting, absorption, and metabolism of the parent drug, a mechanistic approach is not realistic. Therefore, an empirical approach was followed. The "apparent fraction absorption" calculated from plasma levels of DTZ and DTZM was correlated with the in vitro dissolution of DTZ. A Level A correlation between in vitro dissolution and estimated in vivo dissolution starting from the parent drug and its metabolite plasma level was achieved (Figure 8). Both correlations were linear, with correlation coefficients greater than 0.98 .

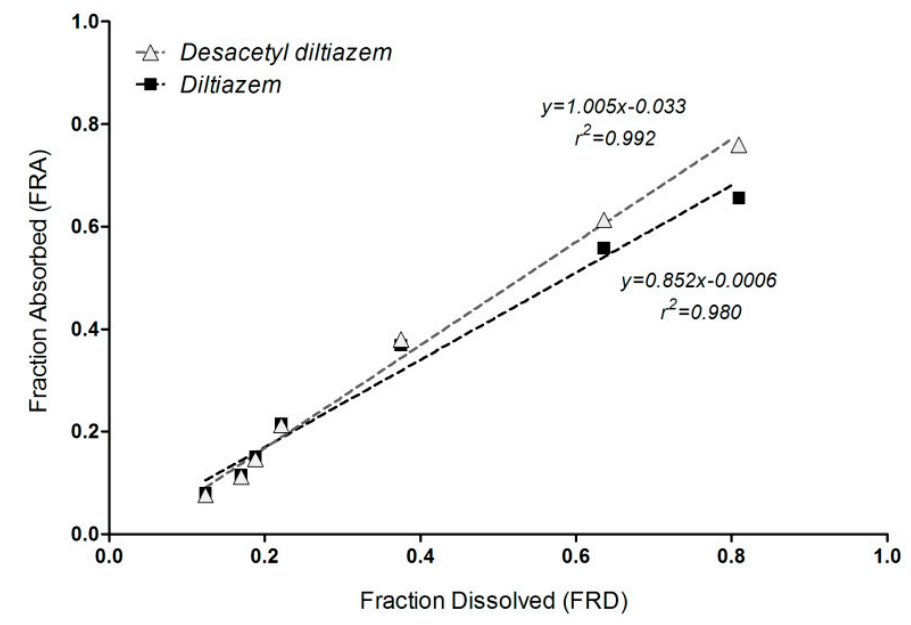

Figure 8. In vitro-in vivo correlation (IVIVC) model for DTZ ( $\mathbf{})$ and DTZM $(\triangle)$.

The slope of the IVIVC model based on "metabolite pharmacokinetics-dissolution of parent drug" is close to 1 , suggesting a superposition of the in vitro dissolution with the in vivo estimated absorption/dissolution from the pharmacokinetics of the metabolite.

\section{Discussion}

Considering the pharmacokinetics of drugs that undergo substantial metabolism, that would be classified as BDDCS (Biopharmaceutics Drug Disposition Classification System) Class 1 and 2 compounds [35], the following essential sequence should be considered: in vivo dissolution (correlated with the in vitro dissolution), absorption, and metabolism of the parent drug.

Since the rate and extent of absorption, and the metabolism are usually high, the slowest rate-determining step for the kinetics of entire process remains the release/dissolution of the parent drug from the pharmaceutical formulation. Consequently, the rate of metabolite appearance in the plasma is determined by the rate and extent of parent drug release and dissolution from the pharmaceutical formulation (Figure 9).

Since DTZ is lipophilic ( $\log P$ 2.79) [31], the transfer rate constant from blood to peripheral compartments is higher than the reverse transport. The rate of return of DTZ to the blood would be small and could be neglected, and the transfer from the blood to the peripheral compartments can be integrated in a total elimination rate constant of the parent drug, $k_{e}^{p d}$ (Figure 10). 


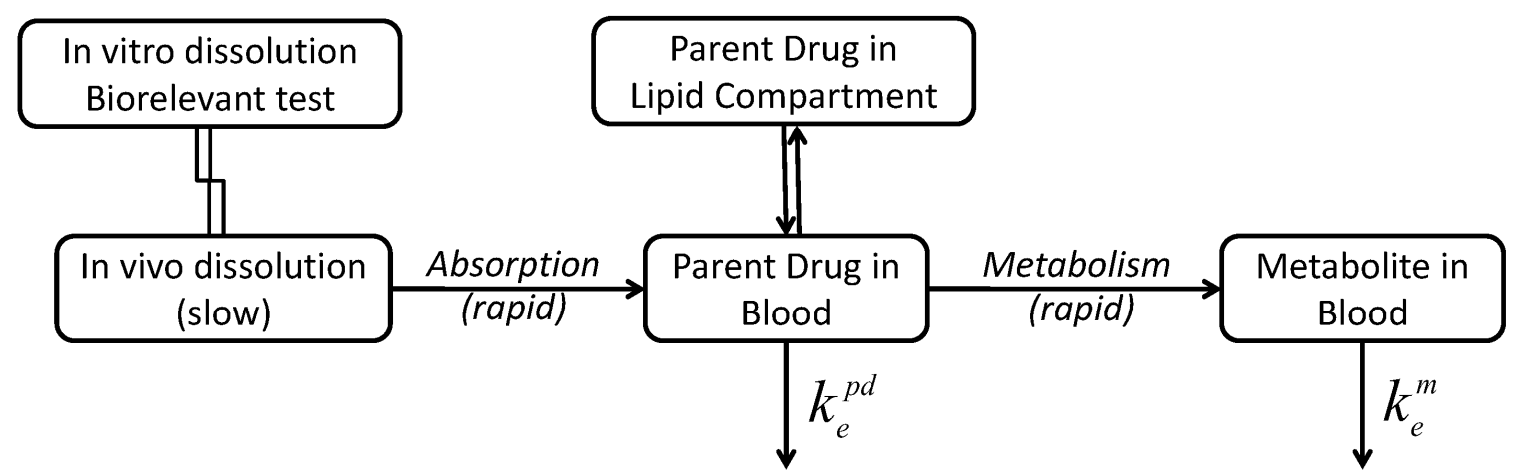

Figure 9. Schematic of processes involved in the pharmacokinetics of drugs that undergo substantial metabolism.

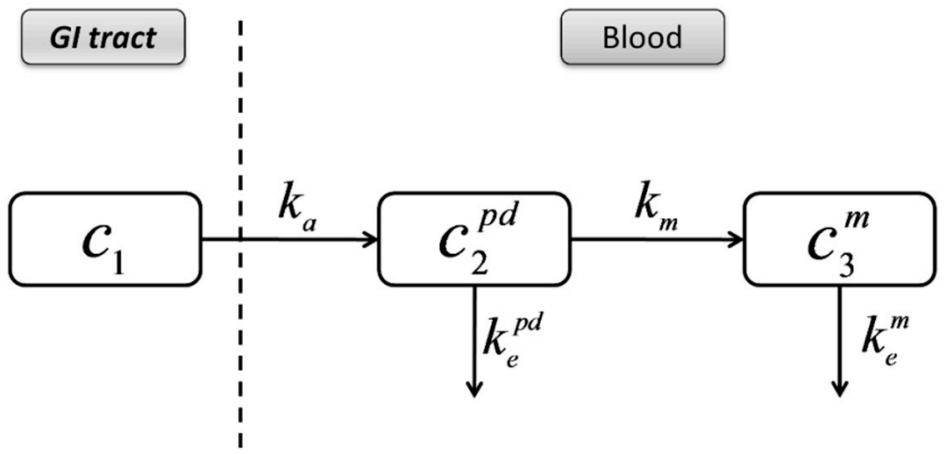

Figure 10. Simplified compartmental model describing the pharmacokinetics of DTZ and DTZM.

If the elimination of the metabolite is not rate limiting (that is when the slowest step is the elimination of the parent drug), the terminal half-life of the metabolite is the same or lower than the terminal half-life of the parent drug. This would be expected, as one of the "objectives" of metabolism is the transformation of drugs in more polar components, for an easier elimination. A one-compartment model can describe the pharmacokinetics of the metabolite, based on the following equation for extravascular administration: $c_{m}(T)=A e^{-k_{a} T}+B e^{-k_{e}^{m} T}$. The apparent absorption rate constant $k_{a}$ is a function of the in vivo dissolution, absorption, distribution, metabolism, and elimination of the parent drug, and $k_{e}^{m}$ is the elimination rate constant for the metabolite. Consequently, it is expected that in vitro dissolution of parent drug - in vivo pharmacokinetics of metabolites correlations are possible for these drugs, and that these correlations account for the entire chain of in vivo processes, i.e., dissolution, absorption, metabolism of the parent drug, and direct appearance of the metabolite in the plasma.

The success of the correlation between the in vitro and in vivo dissolution would depend on the in vitro dissolution method. The good correlations between the in vitro dissolution of DTZ and the apparent absorption of DTZ, suggest that the rate determining process is the in vivo dissolution of the parent drug. In this study a successful prediction of DTZ pharmacokinetics after a single dose based on in vitro data only could be achieved.

\section{Conclusions}

Pharmacokinetic modeling of DTZ and DTZM mean plasma levels suggests a one-compartmental behavior. In the case of DTZ and, more generally, in the case of compounds subjected to extensive metabolism (BDDCS Class 1 and Class 2 compounds), the in vivo dissolution, absorption, metabolism of the parent drug, and the elimination of the metabolite would take place. Since the rate of absorption and the metabolism of BDDCS Class 1 and Class 2 compounds drugs are usually high, the rate of the appearance of the metabolites in the plasma is determined by the rate and extent of parent drug release 
from the pharmaceutical formulation. Under these conditions, a deconvolution method, similar to that of Wagner-Nelson method, can be applied to calculate the absorption and in vivo dissolution of a parent drug starting from the plasma levels of one of its metabolites. The correlation of the estimated in vivo dissolution curves with the in vitro dissolution curves proved to be linear, and in the case of the metabolite a very good superposition of the in vivo and in vitro dissolution kinetics was achieved. Upon further validation with more drugs, this type of correlations could be used for drugs with extensive metabolism, in which the plasma levels of the active metabolites that follow pseudomono-compartmental kinetics are higher than those of the parent drug.

Author Contributions: Conceptualization, C.M., V.A. and N.F.; methodology, V.A. and I.M.; software, V.A.; validation, V.A., N.F. and A.N.; formal analysis, I.M.; investigation, I.M.; resources, C.M.; data curation, A.N.; writing—original draft preparation, V.A.; writing—review and editing, N.F.; visualization, V.A.; supervision, C.M.; project administration, V.A.

Funding: Publication of this work was financially supported by "Carol Davila" University of Medicine and Pharmacy through Contract No. 23PFE/17.10.2018 funded by the Ministry of Research and Innovation within PNCDI III, Program 1-Development of the National RD system, Subprogram 1.2-Institutional Performance-RDI excellence funding projects.

Conflicts of Interest: The authors declare no conflict of interest.

\section{References}

1. Humbert, H.; Bosshardt, H.; Cabiac, M.-D.; Cabiac, M. In Vitro-in Vivo Correlation of a Modified-Release Oral Form of Ketotifen: In Vitro Dissolution Rate Specification. J. Pharm. Sci. 1994, 83, 131-136. [CrossRef] [PubMed]

2. Eddington, N.D.; Marroum, P.; Uppoor, R.; Hussain, A.; Augsburger, L. Development and Internal Validation of an In Vitro-in Vivo Correlation for a Hydrophilic Metoprolol Tartrate Extended Release Tablet Formulation. Pharm. Res. 1998, 15, 466-473. [CrossRef]

3. Mahayni, H.; Rekhi, G.; Uppoor, R.; Marroum, P.; Hussain, A.; Augsburger, L.; Eddington, N. Evaluation of "External" Predictability of an In Vitro-In Vivo Correlation for an Extended-Release Formulation Containing Metoprolol Tartrate. J. Pharm. Sci. 2000, 89, 1354-1361. [CrossRef]

4. Takka, S.; Rajbhandari, S.; Sakr, A. Effect of anionic polymers on the release of propranolol hydrochloride from matrix tablets. Eur. J. Pharm. Biopharm. 2001, 52, 75-82. [CrossRef]

5. Emami, J. In vitro-in vivo correlation: From theory to applications. J. Pharm. Pharm. Sci. 2006, 9, 169-189.

6. Lake, O.; Olling, M.; Barends, D. In vitro/in vivo correlations of dissolution data of carbamazepine immediate release tablets with pharmacokinetic data obtained in healthy volunteers. Eur. J. Pharm. Biopharm. 1999, 48, 13-19. [CrossRef]

7. Varshosaz, J.; Ghafghazi, T.; Raisi, A.; Falamarzian, M. Biopharmaceutical characterization of oral theophylline and aminophylline tablets. Quantitative correlation between dissolution and bioavailability studies. Eur. J. Pharm. Biopharm. 2000, 50, 301-306. [CrossRef]

8. Rao, B.S.; Seshasayana, A.; Saradhi, S.P.; Kumar, N.R.; Narayan, C.P.; Murthy, K.R. Correlation of 'in vitro' release and 'in vivo' absorption characteristics of rifampicin from ethylcellulose coated nonpareil beads. Int. J. Pharm. 2001, 230, 1-9.

9. Al-Behaisi, S.; Antal, I.; Morovján, G.; Szunyog, J.; Drabant, S.; Marton, S.; Klebovich, I. In vitro simulation of food effect on dissolution of deramciclane film-coated tablets and correlation with in vivo data in healthy volunteers. Eur. J. Pharm. Sci. 2002, 15, 157-162. [CrossRef]

10. Mircioiu, C.; Mircioiu, I.; Voicu, V.; Miron, D. Dissolution-Bioequivalence Non-Correlations. Basic Clin. Pharmacol. Toxicol. 2005, 96, 262-264. [CrossRef]

11. Meyer, M.C.; Straughn, A.B.; Mhatre, R.M.; Shah, V.P.; Williams, R.L.; Lesko, L.J. Lack of In Vivo/In Vitro Correlations for $50 \mathrm{mg}$ and $250 \mathrm{mg}$ Primidone Tablets. Pharm. Res. 1998, 15, 1085-1089. [CrossRef]

12. Food and Drug Administration-Center for Drug Evaluation and Research (CDER). Guidance for Industry: Extended Release Oral Dosage Forms: Development, Evaluation, and Application of In Vitro/In Vivo Correlations. Available online: https://www.fda.gov/media/70939/download (accessed on 19 February 2019). 
13. Young, D. Significance of in Vitro in Vivo Correlation (ivivc). In International Bioequivalence Standards: A New Era; Amidon, G.L., Lesko, L.J., Midha, K.K., Shah, V.P., Hilfinger, J.M., Eds.; TSRL: Ann Arbor, MI, USA, 2006; pp. 41-48.

14. USP 34-NF 29. The United States Pharmacopeia 32-the National Formulary 27; United States Pharmacopeial Convention Inc.: Rockville, MD, USA, 2011.

15. Polli, J.E.; Crison, J.R.; Amidon, G.L. Novel approach to the analysis of in vitro-in vivo relationships. J. Pharm. Sci. 1996, 85, 753-760. [CrossRef]

16. Dunne, A.; O’Hara, T.; DeVane, J. A new approach to modelling the relationship between in vitro and in vivo drug dissolution/absorption. Stat. Med. 1999, 18, 1865-1876. [CrossRef]

17. Dunnex, A.; O'Hara, T.; DeVane, J.; Dunne, A. Level A in Vivo-in Vitro Correlation: Nonlinear Models and Statistical Methodology. J. Pharm. Sci. 1997, 86, 1245-1249. [CrossRef]

18. Sirisuth, N.; Augsburger, L.L.; Eddington, N.D. Development and validation of a non-linear IVIVC model for a diltiazem extended release formulation. Biopharm. Drug Dispos. 2002, 23, 1-8. [CrossRef]

19. Parojčić, J.; Ibric, S.; Djurić, Z.; Jovanović, M.; Corrigan, O.I. An investigation into the usefulness of generalized regression neural network analysis in the development of level A in vitro-in vivo correlation. Eur. J. Pharm. Sci. 2007, 30, 264-272. [CrossRef]

20. Corrigan, O.I.; Devlin, Y.; Butler, J. Influence of dissolution medium buffer composition on ketoprofen release from ER products and in vitro-in vivo correlation. Int. J. Pharm. 2003, 254, 147-154. [CrossRef]

21. Mendell-Harary, J.; Dowell, J.; Bigora, S.; Piscitelli, D.; Butler, J.; Farrell, C.; DeVane, J.G.; Young, D. Nonlinear in Vitro-in Vivo Correlations. In Results and Problems in Cell Differentiation; Springer Science and Business Media LLC: Berlin/Heidelberg, Germany, 1997; Volume 423, pp. 199-206.

22. Sandulovici, R.; Prasacu, I.; Mircioiu, C.; Voicu, V.A.; Medvedovici, A.; Anuta, V. Mathematical and phenomenological criteria in selection of pharmacokinetic model for $\mathrm{m} 1$ metabolite of pentoxyphylline. FARMACIA 2009, 57, 235-246.

23. Tvrdonova, M.; Dedik, L.; Mircioiu, C.; Miklovicova, D.; Ďurišová, M. Physiologically Motivated Time-Delay Model to Account for Mechanisms Underlying Enterohepatic Circulation of Piroxicam in Human Beings. Basic Clin. Pharmacol. Toxicol. 2009, 104, 35-42. [CrossRef]

24. Chaffman, M.; Brogden, R.N.; Speight, T.M.; Avery, G.S. A review of its pharmacological properties and therapeutic efficacy. Drugs 1985, 29, 387-454. [CrossRef]

25. Fagan, T.C. Diltiazem: Its place in the antihypertensive armamentarium. J. Cardiovasc. Pharmacol. 1991, 18, S26-S31. [CrossRef]

26. Hermann, P.; Rodger, S.D.; Remones, G.; Thenot, J.P.; London, D.R.; Morselli, P.L. Pharmacokinetics of diltiazem after intravenous and oral administration. Eur. J. Clin. Pharmacol. 1983, 24, 349-352. [CrossRef]

27. Caillé, G.; Boucher, S.; Spénard, J.; Lakhani, Z.; Russell, A.; Thiffault, J.; Grace, M.G. Diltiazem pharmacokinetics in elderly volunteers after single and multiple doses. Eur. J. Drug Metab. Pharmacokinet. 1991, 16, 75-80. [CrossRef]

28. Yeung, P.K.F.; Montague, T.J.; Tsui, B.; McGregor, C. High-Performance Liquid Chromatographic Assay of Diltiazem and Six of Its Metabolites in Plasma: Application to a Pharmacokinetic Study in Healthy Volunteers. J. Pharm. Sci. 1989, 78, 592-597. [CrossRef]

29. Food and Drug Administration-Center for Drug Evaluation and Research (CDER). Guidance for Industry: Bioanalytical Method Validation. Available online: https://www.fda.gov/regulatory-information/search-fdaguidance-documents/bioanalytical-method-validation-guidance-industry (accessed on 26 March 2019).

30. Wagner, J.G.; Nelson, E. Kinetic Analysis of Blood Levels and Urinary Excretion in the Absorptive Phase after Single Doses of Drug. J. Pharm. Sci. 1964, 53, 1392-1403. [CrossRef]

31. Kokate, A.; Li, X.; Williams, P.J.; Singh, P.; Jasti, B.R. In Silico Prediction of Drug Permeability Across Buccal Mucosa. Pharm. Res. 2009, 26, 1130-1139. [CrossRef]

32. Chrenova, J.; Durisova, M.; Mircioui, C.; Dedik, L.; Mircioiu, C. Effect of gastric emptying and entero-hepatic circulation on bioequivalence assessment of ranitidine. Methods Find. Exp. Clin. Pharmacol. 2010, 32, 413. [CrossRef]

33. Marchidanu, D.; Raducanu, N.; Miron, D.S.; Radulescu, F.S.; Anuta, V.; Mircioiu, I.; Prasacu, I. Comparative pharmacokinetics of rifampicin and 25-desacetyl rifampicin in healthy volunteers after single oral dose administration. FARMACIA 2013, 61, 398-410. 
34. Mircioiu, C.; Ionica, G.; Danilceac, A.; Miron, D.; Mircioiu, I.; Radulescu, F.S. Pharmacokinetic and mathematical outliers for drugs with active metabolites. Note i. Model independent analyses for pentoxifylline. FARMACIA 2010, 58, 264-278.

35. Wu, C.Y.; Benet, L.Z. Predicting Drug disposition via application of BCS: Transport/absorption/elimination interplay and development of a biopharmaceutics. drug disposition classification SYSTEM. Pharm. Res. 2005, 22, 11-23. [CrossRef] 